\title{
MANCHESTER
}

1824

列离 Economics

Discussion Paper Series

EDP-1707

\section{Tax evasion, intrinsic motivation, and the evolutionary effects of tax reforms}

\author{
Fabio Lamantia \\ Mario Pezzino
}

February 2017

Economics

School of Social Sciences

The University of Manchester

Manchester M13 9PL 


\title{
Tax evasion, intrinsic motivation, and the evolutionary effects of tax reforms*
}

\author{
Fabio Lamantia \\ Department of Economics, Statistics and Finance \\ University of Calabria (Italy) and \\ School of Social Sciences \\ University of Manchester (UK) \\ fabio.lamantia@unical.it \\ Mario Pezzino ${ }^{\dagger}$ \\ School of Social Sciences \\ University of Manchester (UK) \\ mario.pezzino@manchester.ac.uk
}

March 2017

\begin{abstract}
The paper studies tax evasion in an evolutionary setting. In addition to standard variables such as the fine they may have to pay if found guilty or the probability of being audited, individuals' inclination to engage in tax evasion may also be affected by social interactions. Individuals socially interact with other taxpayers and, doing so, they learn the payoff differential between paying and evading taxes. Moreover, expected payoffs may include reputational costs or rewards awarded by society after an individual is audited. The paper shows that (i) social norms may play a very important role in defining the long run evolution of tax evasion and, consequently, (ii) policymakers should consider reforms that would increase social awareness and information rather than more (financially and politically) expensive traditional auditing instruments; in addition, (iii) fiscal/auditing policies should be carefully tailored to the particular economic and social setting in place in a country.
\end{abstract}

Keywords: tax evasion; pro-social behavior; word of mouth dynamics; tax morale; social-norms marketing. JEL classification: H26, H30, C73.

*The authors gratefully aknowledge financial support from the Institute for Research in Economic and Fiscal Issues.

†Corresponding author. Tel.: +44-1612751383. 


\section{Introduction}

Taxes play an essential role for the finances of a country. Indeed, tax revenues are the basic way a government can finance national expenditure and services to the population. At the same time, taxes are a very important factor that affects the financial decisions of every household and business.

In the attempt to answer the question why individuals evade taxes, the economic literature has taken inspiration from the economics of crime (Becker (1968)) and traditionally framed tax evasion as a gamble. ${ }^{1}$ The key assumption is that no individual, if allowed, would want to pay taxes. Evading taxes then essentially becomes a gamble that individuals may decide to play, depending on their degree of aversion to risk, the probability of being audited and the extent of the possible penalty. ${ }^{2}$ Specifically, this framework predicts high levels of tax evasion if agents face low audit probability or low penalties. This prediction is, however, in contrast to empirical observation. Tax evasion is, indeed, relatively low in many tax systems, in spite of low audit probability and small penalties. Moreover, even in those environments where evading taxes is possible and often a widespread behavior in the society, there are still individuals who act honestly. The literature has identified three possible explanations to this puzzle. One possibility is the existence of a divergence between auditing rates and detection probabilities ${ }^{3}$. Another possibility is that individuals may tend to overestimate detection probabilities. ${ }^{4}$ Finally, individuals may be induced to comply because they experience forms of non-pecuniary motivation. ${ }^{5}$ This paper focuses on this third option. Indeed, in recent years, the interest of economists (but also sociologists, psychologists and political scientists) has gradually focused away from the question "why do people evade taxes?" to the question "why do people pay taxes?". Researchers have attempted to identify and measure the existence and extent of such non-pecuniary incentives, often referred as tax morale. ${ }^{6}$ Luttmer and Singhal (2014) describe various mechanisms according to which tax morale may affect compliance. One mechanism is based on intrinsic motivation. In every society there are individuals who believe that paying taxes is a citizenship duty. In other words, paying taxes is a way to contribute to society's welfare and individuals may obtain private utility from it. ${ }^{7}$ Considering tax morale, in turn, helps also understanding why some individuals may find very difficult to pay taxes. Luttmer and Singhal (2014) describe reciprocity (the utility experienced from paying taxes that depends on

\footnotetext{
${ }^{1}$ See Freire-Serén and Panadés (2013) for a review of the literature.

${ }^{2}$ See for example Allingham and Sandmo (1972), Yitzhaki (1974), Slemrond and Yitzhaki (2002) and Slemrod and Weber (2012).

${ }^{3}$ See Kleven et al. (2011).

${ }^{4}$ See Chetty (2009).

${ }^{5}$ See Andreoni et al. (1998) and Luttmer and Singhal (2014).

${ }^{6}$ Tax morale plays now a key role in empirical research on tax compliance (see Torgler (2007) and Kirchler (2007)). Also, recent psychology literature provides a very useful framework, the so called Slippery Slope model, to study the formation of tax morale and the way it influences tax payers' behavior (see Gangl et al. (2015)).

${ }^{7}$ See, for example, Lubian and Zarri (2011) and Dwenger et al. (2014).
} 
the individual's relationship with the government) as another mechanism of tax morale. In those countries in which governments are considered particularly corrupted or inefficient, tax morale may, therefore, be very low. ${ }^{8}$ There is another important aspect of taxpayers' behavior related to tax morale and that is the role that social norms and reputation may play. ${ }^{9}$ The way society sees the pro-social actions of an individual may have an important reputational effect on the utility that the individual obtains from performing a particular task. Charity, voluntary work and donations are examples of actions that may improve individuals' reputation. Bénabou and Tirole (2006) show why standard financial incentives may be counterproductive in those situations in which reputation effects may induce motivated agents to reduce their pro-social effort, fearing to be seen as greedy by society. Indeed, reputation may play an important role when individuals have to consider reporting their income for tax purposes. If audited and found guilty of tax evasion, there may be a significant social cost, in addition to a standard fine, that the individual has to face. Similarly, if audited and found not guilty, the individual may be rewarded with a reputation of honestly and citizenship.

Myles and Naylor (1996), Kim (2003) and Traxler (2010) are examples of contributions in the literature that have attempted to incorporate tax morale directly into the Allingham and Sandmo (1972)'s framework. Essentially tax morale is modeled as an internalized social norm that makes tax evasion more costly, affecting the individuals' decisions under risk. These contributions employ a static approach to study the problem. However, introducing tax morale has often the effect of generating multiple equilibria. This poses the necessity to introduce dynamic adjustments to solve equilibrium selection problems and study the long run evolution of tax evasion. Indeed, Luttmer and Singhal (2014) identify long run cultural factors as a significant variable that affects tax morale and compliance. ${ }^{10}$ This is important. When considering the effects of social norms and reputation on individuals' actions, a static model may be inadequate and the role played by a continuously evolving cultural framework should be carefully considered. It should be natural to think, therefore, of the individuals' decisions in a dynamic setting. As Besley and Persson (2014) also point out, the ability of a country to enforce compliance may be affected by sociological and cultural factors and, in turn, it may be a key factor defining the development trajectory of a whole economy. Most of the theoretical works on tax compliance to date are, however, "one-shot" in nature (see Luttmer and Singhal (2014)). To our knowledge, the only paper that considers intrinsic motivation, social norms and reputation in a dynamic setting with tax evasion is Besley et al. (2015). The paper is a dynamic extension of Bénabou and Tirole (2006) where individuals internalize in their utility the reputational benefit/cost of paying/evading taxes in the previous year. The authors assume that indi-

\footnotetext{
${ }^{8}$ See for example Frey (2003), Frey and Torgler (2007), Alm and Torgler (2006), Alm et al. (2010), Cumming et al. (2009), Barone and Mocetti (2011).

${ }^{9}$ See Hallsworth et al. (2014).

${ }^{10}$ Empirical evidence, based on survey data, of the effects of cultural factors is provided in DeBacker et al. (2015) and Kountouris and Remoundou (2013).
} 
viduals every year need to decide whether to evade taxes. Their decision will depend on their intrinsic motivation, the extent of the fine if found guilty and the reputational cost of tax evasion. The authors also empirically study the effects of a temporary introduction of a poll tax in Britain. They show that tax evasion increased after the introduction of the poll tax (due to a negative effect in intrinsic motivation/reciprocity). Interestingly, tax evasion continued to persist even after the poll tax was abolished (possibly highlighting the dynamic effects of social norms produced by the existence of a social multiplier).

Our paper shares with Besley et al.(2015) the recognition of the importance of a dynamic analysis of tax evasion. To do so, however, we take a different approach and consider an evolutionary game with word of mouth dynamics. Specifically, our paper contributes to the literature in three ways.

First, in line with Besley et al.(2015) we study tax evasion using a dynamic setting. Besley et al.(2015), however, do not describe how reputational costs and rewards are connected to the social norms accordint to which individuals interact. In line with related contributions that study pro-social behavior, in Besley et al.(2015) the strength of social norms is expressed by an exogenous parameter. Our aim is to explicitly model the way reputational costs and benefits enter the utility of taxpayers. In our framework a particularly important feature of the way reputation affects the utility of individuals is that it depends in each period on the particular social practices of the society we are considering. For example, being a honest taxpayer in a country where tax evasion is the norm may create a larger reputational effect compared to the same behavior in a country where honest reports are, instead, the majority. Similarly, being found guilty in a country where most of the population evades taxes may be less costly in terms of reputation than being found guilty in a mostly honest country. While in Besley et al.(2015) individuals' reputation is affected by their decision to pay or evade taxes in the previous period, in our model the extent of the social cost/benefit on a dishonest/honest individual depends on how widespread a phenomenon tax evasion is in the society. ${ }^{11}$

Second, Besley et al.(2015) study long run equilibria employing standard adaptive dynamics. In our model, instead, the dynamic development of tax evasion is described in the form of evolutionary dynamics. Individuals are assumed to be "programmed" to behave honestly or dishonestly. Whether one or the other (or both) behavior survives in the society is determined by an evolutionary adaptation process, that depends on the expected payoffs of individuals. In standard evolutionary games it is assumed that individuals are able to compare their expected payoffs to the expected payoffs of the whole population. This is somewhat implausible when considering the decision to evade taxes of an individual. It seems more plausible, instead, to imagine that an individual will be able to compare his/her payoffs with the payoffs of those individuals with whom he/she has been socially interacting. This is in line with those contribu-

\footnotetext{
${ }^{11}$ This feature of our model is in line with Traxler (2010). However, our framework considers a more complex set of social norms and reputational effects (see Section 5). In fact, we consider the possibility that honest/dishonest behaviour can be punished/rewarded by some types of societies.
} 
tions in the literature that stress the importance of network formation and the way the network of relationships may influence individuals' conduct. ${ }^{12}$ In our model we consider a word of mouth process where in each period one individual meets another. If both individuals are of the same type (honest/dishonest), then they have no information to wage the advantages of choosing a different behavior. However, if an individual meets a taxpayer of a different type, then they can learn and possibly change their behavior. The probability of facing a taxevader will depend on the level of tax evasion in a certain period.

Finally, Besley et al.(2015) study a tax system in which all individuals belonging to a local council earn the same income and, therefore, face the same tax rate. In contrast, we explicitly describe a progressive tax system with two bands and two tax rates. This allows us to study what is the effect on the dynamics of tax evasion of changes in tax rates and the possibility of a reform toward a flat rate system. This feature of our model helps us to acquire a better understanding of the effects that have been produced by recent reforms in various countries, with a particularly important example provided by Russia. In 2001 a progressive tax system with rates $12 \%, 20 \%$ and $30 \%$ was replaced in Russia by a flat tax rate of $13 \%$. Interestingly Gorodnichenko et al. (2009) empirically showed that the reform produced a reduction in tax evasion. Our model can help explain this result.

Our dynamic analysis shows that the existence and the attributes (including stability) of the long run equilibria defining the level of tax evasion in a country significantly depend on the parameters that describe tax morale, social norms and reputational effects. In addition, the dynamic trajectories of the evolution of tax evasion depend on the initial conditions of the model. This implies that two (both economically and socially) identical countries may experience very different levels of tax evasion in the long run if the initial levels of evasion differ significantly. Supported by these results, the paper shows that the social norms and framework where tax evasion takes place play a very important role in guiding individuals' actions. This result produces two important implications. First, policymakers should consider reforms that would modify social awareness, social norms and reputational incentives, rather than (or in addition to) more (financially and politically) expensive standard fiscal instruments. ${ }^{13}$ Second, it is essential to carefully understand the social norms of a country and in particular the effects that tax reforms may produce depending on the particular social framework. In other words, simply replicating tax reforms that have proved to be successful abroad may produce unexpected and perverse long run effects in another country.

The paper is organised as follows. Section 2 introduces the model. Section 3 describes some important policy implications based on comparative statics analysis. Section 4 describes the dynamic analysis. Section 5 generalizes the

\footnotetext{
${ }^{12}$ See, for example, Sutcliffe et al. (2012) and van Dolder and Buskens (2014).

${ }^{13}$ Filippin et al. (2013) use microdata on opinions about taxation included in the Survey on Household Income and Wealth in Italy in 2004. The results suggest that tax enforcement affects tax morale. Lago-Peñas and Lago-Peñas (2010) find that a high tax burden makes the taxpayers feel entitled to evade.
} 
analysis and our treatment of tax morale discussing how the results are affected by introducing different classes of social norms representing different societies and cultures. Section 6 concludes.

\section{The model}

Consider a population of taxpayers of unit mass. Suppose that there are only two possible levels of income, $0<Y_{L}<Y_{H}$, that can be earned. A fraction $\gamma \in[0,1]$ represents the portion of the population with high income $Y_{H}$. The remaining portion of the population earns, instead, low income $Y_{L}$.

Suppose that a progressive tax system is in place, with tax rates $0<t_{L}<$ $t_{H}<1$. Taxpayers need to report their taxable income. Agents who report income $Y_{L}$ pay taxes $t_{L} Y_{L}$, while agents who report income $Y_{H}$ pay taxes $t_{L} Y_{L}+$ $t_{H}\left(Y_{H}-Y_{L}\right)$. Obviously, low income agents have no incentive to report a level of income other than $Y_{L}$. High income taxpayers, however, may find desirable to evade taxes reporting a level of income equal to $Y_{L}$. Let us define $r \in[0,1]$ the portion of high income agents who decide to evade taxes. Suppose that with probability $p \in[0,1]$ an agent is audited by the tax authority. Let us assume that, if audited, a dishonest agent is found guilty with certainty. If high income agents have truthfully reported their income $Y_{H}$, then they enjoy a positive reputational effect for being exposed to society as honest taxpayers. We assume that this reputation effect increases as the share of dishonest agents in the population increases. The reputational benefit for being proved honest is

$$
r \zeta
$$

with $\zeta>0$. If, instead, a high income agent, who has decided to evade taxes and report income $Y_{L}$, is audited and charged with tax evasion, (s)he will have to pay a fine equal to $M$ on top of the increment in taxes $t_{H}\left(Y_{H}-Y_{L}\right)$. Being found guilty of tax evasion has also a negative effect on the utility of the taxevader because of the reputational costs. Indeed, being recognized by society as a taxevader creates a reputational cost for the dishonest agent. We assume that this social shaming effect increases as the share of honest agents increases. ${ }^{14}$ The reputational cost for the dishonest agent is equal to

$$
(1-r) \theta
$$

with $\theta>0$.

The set of social norms and reputational effects described here is clearly a simplification, but it does provide important insights to the problem that will be described in section 3 and 4 . In section 5 we shall consider how results change when different classes of social norms and tax morale are introduced.

Considering reputation and shaming effects, the utility of an honest highincome taxpayer is

\footnotetext{
${ }^{14}$ In line with Frey and Torgler (2007) and Traxler (2010) we assume that tax morale and, in particular, the reputational effects of social norms depend on the degree of compliance in a country.
} 


$$
U_{h}=\left\{\begin{array}{l}
U_{h N}=Y_{L}\left(1-t_{L}\right)+\left(Y_{H}-Y_{L}\right)\left(1-t_{H}\right) \text { if not audited } \\
U_{h A}=Y_{L}\left(1-t_{L}\right)+\left(Y_{H}-Y_{L}\right)\left(1-t_{H}\right)+r \zeta \text { if audited }
\end{array}\right.
$$

whereas the utility of a dishonest high-income taxpayer is

$$
U_{d}=\left\{\begin{array}{c}
U_{d N}=\left(Y_{H}-Y_{L} t_{L}\right) \text { if not audited } \\
U_{d A}=Y_{L}\left(1-t_{L}\right)+\left(Y_{H}-Y_{L}\right)\left(1-t_{H}\right)-M-\vartheta(1-r) \text { if audited }
\end{array}\right.
$$

The (certain) utilities of a low income agent is

$$
U_{L}=Y_{L}\left(1-t_{L}\right)
$$

Timing unravels as follows. At the beginning of each period all agents report their income and pay taxes. With probability $p$ they are audited by the tax agency. After auditing, two agents are randomly selected and matched by nature from the population. The two selected agents learn whether the agent they have been put in contact with has been audited and whether (s)he has been found guilty of tax evasion.

\section{Comparative statics analysis}

The expected utility, at time $t$, of a dishonest agent is

$$
\mathbb{E}\left[U_{d}\right]=p U_{d A}+(1-p) U_{d N}
$$

whereas the expected utility, at time $t$, of a honest agent is

$$
\mathbb{E}\left[U_{h}\right]=p U_{h A}+(1-p) U_{h N}
$$

For easing the notation, denote the difference in expected utilities by

$$
y(r)=\mathbb{E}\left[U_{d}\right]-\mathbb{E}\left[U_{h}\right]
$$

Function $y(r)$ is often referred to as the "score" function. ${ }^{15}$ Expected utilities from the two behaviors are equal for a fraction $r^{*}$ when $y\left(r^{*}\right)=\mathbb{E}\left[U_{d}\right]-\mathbb{E}\left[U_{h}\right]=$ 0 , which gives the unique possible equilibrium of the system

$$
r^{*}=\frac{t_{H}(1-p)\left(Y_{H}-Y_{L}\right)-p(\theta+M)}{p(\zeta-\theta)}
$$

Moreover, it is $r^{*} \in(0,1)$ in the following cases:

1. $0<\zeta<\vartheta$ and $\widehat{t}_{H}<t_{H}<\widetilde{t}_{H}$, or

\footnotetext{
${ }^{15}$ The difference of expected utilities between different agents is meaningful as we assumed that they are ex-ante identical.
} 
2. $0<\vartheta<\zeta$ and $\widetilde{t}_{H}<t_{H}<\widehat{t}_{H}$, where

$$
\begin{aligned}
& \widehat{t}_{H}:=\frac{p(M+\zeta)}{(1-p)\left(Y_{H}-Y_{L}\right)} \\
& \widetilde{t}_{H}:=\frac{p(M+\theta)}{(1-p)\left(Y_{H}-Y_{L}\right)}
\end{aligned}
$$

Notice that $r^{*}=0$ for $t_{H}=\frac{p(M+\vartheta)}{(1-p)\left(Y_{H}-Y_{L}\right)}$ and $r^{*}=1$ for $t_{H}=\frac{p(M+\zeta)}{(1-p)\left(Y_{H}-Y_{L}\right)}$.

In the next section we study the dynamic stability of the system and show that only when $\zeta>\theta$ an interior equilibrium $r=r^{*} \in(0,1)$ may be (locally asymptotically) stable. It is easy to show that if $\zeta>\theta$, then the sign of $\frac{d r^{*}}{d M}, \frac{d r^{*}}{d \vartheta}$, $\frac{d r^{*}}{d \zeta}, \frac{d r^{*}}{d p}, \frac{d r^{*}}{d Y_{H}}, \frac{d r^{*}}{d Y L}$ is negative and $\frac{d r^{*}}{d t_{H}}$ is positive.

This simple comparative statics analysis produces already interesting indications. First, $\frac{d r^{*}}{d t_{H}}>0$ implies that an increase in the tax rate for the wealthier group of individuals increases tax evasion. In other words, a higher tax rate makes tax evasion more profitable for individuals. This is intuitive. Nonetheless our result stands in contrast to previous theoretical contributions showing that tax evasion tends to decrease if the tax rate increases (see Yitzhaki (1974)). A consequence of this result is that if the high tax rate is lowered, to the limit, to match $t_{L}$, introducing in other words a flat rate system, then ceteris paribus tax evasion would decreases.

$\frac{d r^{*}}{d M}<0$ and $\frac{d r^{*}}{d p}<0$ show that standard auditing instruments to fight tax evasion may be effective. These instruments, however, usually come at a cost for every government. The cost is both financial, since auditing is in general expensive, and political, since a government that intends to harshly fight tax evasion may be seen as oppressive and greedy. For this reason, the fact that $\frac{d r^{*}}{d \theta}<0$ and $\frac{d r^{*}}{d \zeta}<0$ is very important. Policies and public campaigns that increase social awareness towards tax evasion and citizenship may be a cheaper (financially and politically) and, nonetheless, effective alternative to auditing. In this sense, approaches that consider naming and shaming or commending taxevaders/payers may be desirable.

\section{Word of mouth}

In this section, we endogenize $r$, the fraction of high income agents who decide to evade taxes, by considering the average payoff obtained by each strategy. It is reasonable to assume that at time $t$ the probability of being dishonest is approximated by the fraction $r$ of dishonest agents in the population at that time. Then, this probability is updated according to the expected utilities from the two possible behaviors (honest or dishonest), as specified below. This way, an updated fraction of high income agents that will evade taxes at time $t+1$ is 
obtained. We model the dynamics of the probability of being dishonest by the word of mouth evolutionary framework proposed by Dawid (1999). ${ }^{16}$

Suppose that at each (discrete) time period two (high income) agents meet and compare their positions. If both agents have the same behavior (either both honest or both dishonest), they have the same utility and no need for switching behavior arises. However, if one honest taxpayer meets a dishonest taxpayer, they could reconsider their behavior according to the utility obtained by the other agent. Thus, an honest agent may change her mind if she meets a dishonest and their utility is different. Clearly, the higher the difference is between the dishonest and the honest's utility, the more likely the honest will become dishonest. Define by $\Phi$ the probability of switching behavior from honest to dishonest given that $U_{d} \geq U_{h}$, and denote it by $\Phi\left(U_{d}-U_{h}\right)$ :

$$
\Phi\left(U_{d}-U_{h}\right)=\mathbb{P}\left(h \rightarrow d \mid U_{d} \geq U_{h}\right)
$$

$\Phi$, being a probability distribution function, is non-decreasing in its argument $y=U_{d}-U_{h}$ with

$$
\begin{aligned}
& \lim _{y \rightarrow-\infty} \Phi(y)=0 \\
& \lim _{y \rightarrow+\infty} \Phi(y)=1
\end{aligned}
$$

All in all, the probability $p_{h \rightarrow d}$ that an honest becomes dishonest is given by the probability that an honest meets a dishonest, which is $r$, times the probability $\Phi$ to change behavior, namely

$$
p_{h \rightarrow d}=r \Phi(y)
$$

from which it follows that the probability to remain honest is $p_{h \rightarrow h}=1-p_{h \rightarrow d}$. Analogously, a dishonest agent can become honest with a probability given by the probability that (s)he meets an honest, which is $(1-r)$, times the probability $\Psi$ that a dishonest becomes honest, given the difference in utilities $U_{h}-U_{d}$. Clearly, $\Psi(-y)=1-\Phi(y)$, so that the overall probability that a dishonest becomes honest is

$$
p_{d \rightarrow h}=(1-r)[1-\Phi(y)]
$$

with an obvious meaning of the notation. Finally, it is $p_{d \rightarrow d}=1-p_{d \rightarrow h}$.

Suppose that the matching between agents of the population is uniform and that a large number of sampling from the population is taken. This way, the average utility difference of the two behaviors is well approximated by the expected difference (3).

\footnotetext{
${ }^{16}$ Here we explain the evolutionary dynamics along the lines of the classical biological interpretation of replicator dynamics. However, with human beings the behavior of an agent can be updated even within the same generation, as one can change her mind (i.e. switch the kind of behavior) by observing the performance of other agents. A similar modeling structure as the one here proposed has been employed in evolutionary oligopolies to investigate competition where players have different information sets or different objective functions, see Bischi et al. (2015), Cerboni Baiardi et al. (2015), Droste et al. (2002), Kopel et al. (2014), De Giovanni and Lamantia (2016).
} 
From now on, we denote by $r_{t}$ the fraction of dishonest taxpayers, where $t$ emphasizes its dependence on time. Notice that, because of the reputational effects of auditing, the expected payoffs are functions of the fraction $r_{t}$, i.e. $\mathbb{E}\left[U_{d}\right]=\mathbb{E}\left[U_{d}\left(r_{t}\right)\right], \mathbb{E}\left[U_{h}\right]=\mathbb{E}\left[U_{h}\left(r_{t}\right)\right]$ and $y=y\left(r_{t}\right)$.

The dynamics of the probability $r_{t}$ can be written as follows:

$$
\begin{aligned}
r_{t+1} & =r_{t}+\underbrace{\left(1-r_{t}\right) p_{h \rightarrow d}}_{\begin{array}{c}
\text { share of honest agents } \\
\text { becoming dishonest }
\end{array}}-\underbrace{r_{t} p_{d \rightarrow h}}_{\begin{array}{c}
\text { share of dishonest agents } \\
\text { becoming honest }
\end{array}} \\
& =r_{t}+r_{t}\left(1-r_{t}\right) \Phi\left(y\left(r_{t}\right)\right)-r_{t}\left(1-r_{t}\right)\left[1-\Phi\left(y\left(r_{t}\right)\right)\right]
\end{aligned}
$$

which can be rewritten as the unidimensional map

$$
r_{t+1}=r_{t}\left[1+\left(1-r_{t}\right) G\left(y\left(r_{t}\right)\right)\right]
$$

where $G(x)=2 \Phi(x)-1$. Equation (6) can be described as a balance equation: the fraction of dishonest agents at time $t+1, r_{t+1}$, is increased by the expected fraction of agents that decide to become dishonest, $\left(1-r_{t}\right) p_{h \rightarrow d}$, and decreased by the expected fraction of agents that decide to become honest, $r_{t} p_{d \rightarrow h}$. $G$ inherits from $\Phi$ the following properties:

$$
\begin{aligned}
& \lim _{y \rightarrow-\infty} G(y)=-1 \\
& \lim _{y \rightarrow+\infty} G(y)=1
\end{aligned}
$$

Moreover, being $\Phi$ a distribution function, by assuming unimodality and symmetry of the corresponding density function, the following assumptions on $G$ hold:

1. $G(0)=0$;

2. $G$ is odd (symmetric with respect to 0 );

3. $G$ is increasing;

4. $G$ is convex in $(-\infty, 0)$ and concave in $(0,+\infty)$;

5. $G$ is differentiable at least in $y=0 .{ }^{17}$

One important property of map (7) is the following. For a given $r_{t} \in(0,1)$ it is $r_{t+1}>r_{t}[<]$ if and only if $G\left(y\left(r_{t}\right)\right)>0[<0]$. By monotonicity of $G($.$) , the$ sign of $G($.$) coincides with the sign of y(r)$, so that an increment (decrement) in the share $r$ occurs if and only if $y(r)>0[<0]$. By this property, we can say that the dynamical system (7) is a particular example of monotone selection dynamics, see Cressman (2003) and Weibull (1995) for details.

${ }^{17}$ A possible specification for $G(x)$ is $G(x)=\frac{2}{\pi} \arctan \left(\frac{\lambda}{2} \pi x\right)$, see Bischi et al. (2009), where $\lambda=G^{\prime}(0)>0$ is a parameter that model the intensity of choice, i.e. in our context the willingness to change behavior from honest to dishonest for chasing utility differential $y(r)$ over time. This functional form satisfies all the required assumptions to be employed in (7). We shall adopt this specification in the numerical analysis provided in Section 5. 


\subsection{Dynamics}

This section is devoted to the analysis of the discrete-time system (7), which models how the fraction of dishonest agents evolve over time. Map (7) admits two kinds of fixed points:

- boundary equilibria, $r^{0}=0$ and $r^{1}=1$;

- inner equilibria, which are any $r^{*} \in(0,1)$ such that $y\left(r^{*}\right)=0$, i.e. such that expected utilities of behaving honestly or dishonestly are equal, $\mathbb{E}\left(U_{h}\right)=\mathbb{E}\left(U_{d}\right)$, see (4).

On one hand, boundary equilibria exist for all parameters values and correspond to monomorphic population configurations where all agents are honest $\left(r_{0}=0\right)$ or dishonest $\left(r_{1}=1\right)$. On the other hand, the inner equilibrium $r^{*}$ in (4) only exists when the tax rate $t_{H}$ belongs to given intervals, as we remarked before, see (5); $r^{*}$ corresponds to a polymorphic configuration of the population of high income taxpayers where both honest and dishonest agents are present. For this inner equilibrium, one important question is related to its stability: what happens when the system is in a state that is different from the equilibrium? Will the generic trajectory converge to equilibrium $r^{*}$ or not? We answer these questions in Proposition 1. In Proposition A.1 in the Appendix we report the full description of the adjustment dynamics of map (7).

\section{Proposition 1}

Consider the adjustment dynamics modelled by map (7) and the thresholds levels $\widetilde{t}_{H}$ and $\widehat{t}_{H}$ in (5).

The inner equilibrium $r^{*}$ in (4) is asymptotically stable with basin of attraction $\mathcal{B}\left(r^{*}\right)=(0,1)$ iff $\widetilde{t}_{H}<t_{H}<\widehat{t}_{H}$ and $\zeta>\theta>0$ and the following "non-overshooting" condition holds:

$$
G^{\prime}(0) \in\left(0, \frac{2}{p\left(1-r^{*}\right) r^{*}(\zeta-\theta)}\right)
$$

At $G^{\prime}(0)=\frac{2}{p\left(1-r^{*}\right) r^{*}(\zeta-\theta)}$, equilibrium $r^{*}$ looses stability through a perioddoubling bifurcation, with the appearance of cyclic or chaotic motion as parameter $G^{\prime}(0)$ is further increased.

An interior equilibrium, where only a portion $r^{*} \in(0,1)$ of the population decides to evade taxes can be meaningful and stable only for intermediate values of $t_{H}$ and $\zeta>\theta$. An intermediate $t_{H}$ ensures that a portion of the population in equilibrium may find profitable to evade and at the same time the remaining portion may find optimal to pay taxes honestly. In addition, it is necessary that $\zeta>\theta$ for $r^{*} \in(0,1)$ to be a stable equilibrium. In other words, only a system that has in place social norms that prioritize commending and nurturing honest behavior rather than naming and shaming tax evasion can reach a stable interior equilibrium. If instead $\zeta<\theta$, in the long run the system will converge 
to full honestly or full tax evasion, depending on the particular original value of $r$.

An implication of Proposition 1 (described in detail in Proposition A.1 in the Appendix) is that regardless of the benefits/costs created by social norms and pro-social behavior, the system may reach corner solutions for extreme values of the tax rate $t_{H}$. This is intuitive. If $t_{H}$ is sufficiently low, then the expected pay-off of those individuals who honestly pay taxes is higher compared to the pay-off of those who evade taxes. Evolutionary dynamics will take the system to a stable equilibrium in which all individuals would pay taxes and tax evasion disappears. The other extreme is produced when $t_{H}$ is sufficiently high. Now tax evasion may be a profitable alternative to pay taxes honestly. Evolutionary dynamics would take the system to a stable equilibrium in which all individuals evade taxes. These two extremes show how important it is to understand the long run as much as the short run effects of fiscal policies. Changes in tax rates may have short run positive effects on tax revenue collection, but they may also bring catastrophic long run effects.

A final comment before moving to a discussion of the effects of tax morale and more realistic types of social norms. We argued that, regardless of the benefits/costs created by social norms and pro-social behavior, a level of $t_{H}$ sufficiently low would ensure low or no tax evasion in the long run. As long as $t_{L}<\max \left[\widehat{t}_{H}, \widetilde{t}_{H}\right]$, then a reduction in $t_{H}$ would produce an evolutionary path towards a reduction of tax evasion. Indeed, for $t_{L}<\max \left[\widehat{t}_{H}, \widetilde{t}_{H}\right]$, allowing $t_{H} \rightarrow t_{L}$ (in other words introducing a flat rate $t=t_{H}=t_{L}$ ) would ensure that a strictly positive portion of the population will pay taxes honestly. In addition, this honest portion of the population will be higher the lower will be the flat rate. This result provides a dynamic and behavioral explanation of the reduction in tax evasion experienced in Russia after the adoption of a flat rate system in 2001.

\section{Social norms and tax morale}

In Section 4 we showed that reputation (described by parameters $\zeta$ and $\theta$ ) can play a very important role in defining individuals' behavior and, ultimately, the degree of tax evasion in the long run. The reputational rewards/costs that we have considered so far implicitly assumed a very specific configuration of social norms. In other words, it was assumed that society rewarded (if honest) and punished (if dishonest) in an increasing measure individuals that acted in contrast to the majority of the population. In this section we provide a more general and realistic description of society and we explicitly model social norms in the reputational rewards and costs.

If audited, honest taxpayers now internalize in their utility function the following reputational rewards/costs

$$
R_{h}=\zeta\{r+K[(\beta-r) r-r]\}
$$

where $\zeta>0, K \in[0,1]$ and $\beta \geq 0$. In Section 4 we effectively considered the case 
$K=0$. In what follows, we assume $K=1$ and disregard intermediate values of $K$ for which the results are analogous to the case $K=1$. $\zeta$ describes again the scale of the reputational effect of being identified as a honest agent. However, the extent of the reputational effect now depends also on social norms as described by parameter $\beta$. Specifically, $\beta$ describes the extent of the level of society's appreciation for honest behavior. Indeed, notice that if $\beta \geq 2$, then $R_{h}$ is monotonically increasing in $r$. This scenario describes a society in which honest behavior is more rewarded the higher is the level of tax evasion in the population. In other words, this reputation effect increases as the share of dishonest agents in the population increases. Qualitatively this scenario replicates the same society that we have studied in Section 4 . If $\beta<2$, however, $R_{h}$ is maximized for some value of $r$ between 0 and 1 . The model now describes a society where honest taxpayers obtain a positive reputation that increases in $r$ only if a small portion of the population engages in tax evasion. However, if $r$ is sufficiently large $(r>\beta / 2)$, then honest behavior (seen as an action against conformity to social practices) tends to be less appreciated by society. ${ }^{18}$ Eventually, for $\beta$ sufficiently small $(\beta<1)$ and $r$ relatively large $(r>\beta)$, honest behavior will be disliked by society, who may now assign a bad reputation to honest taxpayers. In this scenario honest individuals are effectively discriminated for going against the majority of the population.

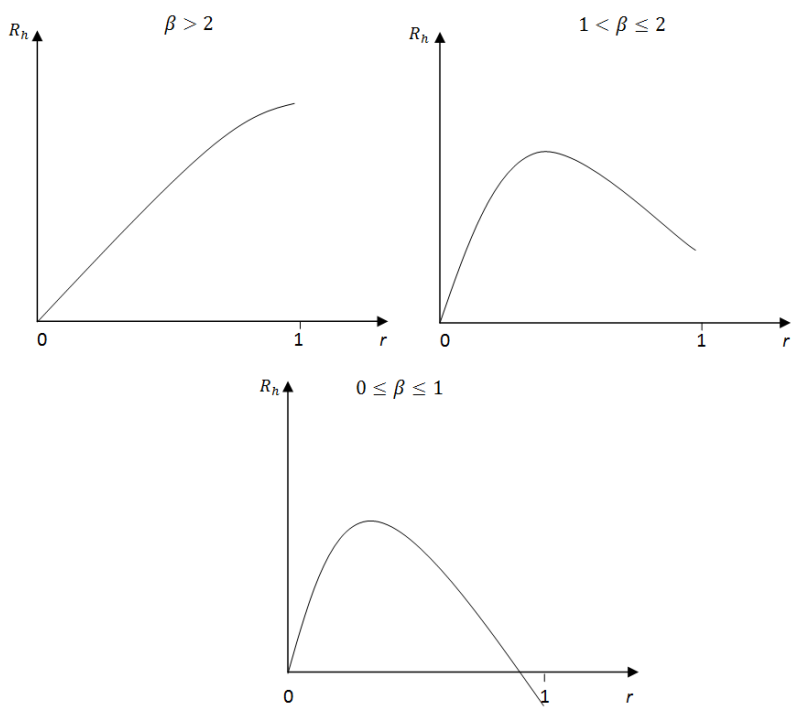

Figure 1: Benefit of honest reputation as a function of social practices $(r)$ in relation to social norms $(\beta)$

\footnotetext{
${ }^{18}$ The fact that reputation may be influenced by the way an individual's behavior conforms to the practices of a society is known as normative social influence in social psychology literature. See, for example, Terry and Hogg (2001).
} 
Social norms can also affect the reputational cost of dishonest agents. Suppose that the reputation cost of being found guilty of tax evasion is now equal to

$$
R_{d}=-\theta\{(1-r)+K[(\beta-r)-(1-r)]\}
$$

with $\theta>0$ describing again the scale of the reputational effect of being identified as a dishonest agent. ${ }^{19}$ Similar to case of honest agents, we shall focus on the case where $K=1$. Social norms towards tax evasion are again described by parameter $\beta$. A $\beta$ sufficiently large $(\beta \geq 1)$ describes a society that clearly dislikes dishonest behavior and, therefore, $R_{d}$ represents the disutility experienced by dishonest individuals for any value of $r$. In addition, notice that the reputational cost of tax evasion is highest when the dishonest agent operates in an environment in which most individuals honestly pay taxes. Interestingly, a smaller $\beta(\beta<1)$ would describe, instead, a society more lenient toward tax evasion. If only a small portion of the population evades taxes $(r<\beta)$, dishonest individuals still obtain a negative reputation effect. However, if tax evasion is a more widespread phenomenon in the society $(r>\beta)$, then dishonest individuals may even obtain a positive reputation. In other words, they are recognized a "smart" and the conformity of their actions to the practices of the majority of society is rewarded..$^{20}$

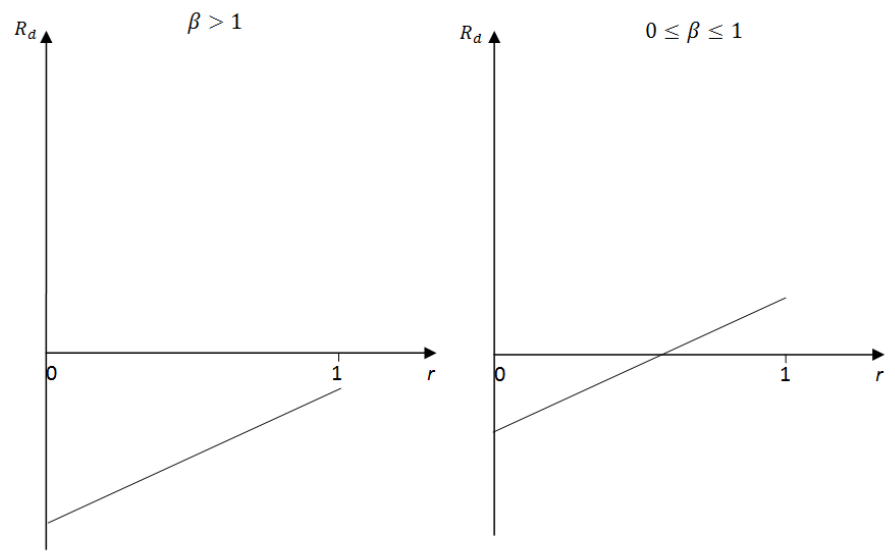

Figure 2: Effects of dishonest reputation as a function of social practices $(r)$ in relation to social norms $(\beta)$

\footnotetext{
${ }^{19}$ The linearity of $R_{d}$ qualitatively does not affect the main insights of the analysis while ensuring the tractability of the model.

${ }^{20} \mathrm{In}$ the latest US presidential elections the issue of dubious tax strategies employed by one of the candidates has been raised in numerous occasions (see http://www.nytimes.com/2016/11/01/us/politics/donald-trump-tax.html?_r=0). The candidate and his supporters have also explicitly described his actions as "smart" (see http://edition.cnn.com/2016/09/26/politics/donald-trump-federal-income-taxes-smartdebate/).
} 
Let us also assume that honest taxpayers experience an extra utility arising from tax morale of the form

$$
\alpha t_{H}\left(Y_{H}-Y_{L}\right)
$$

where $\alpha \in[-1,1]$. A value of $\alpha>0$ denotes a positive tax morale, i.e. the taxpayer obtains an extra benefit from paying high taxes, for example because of its contribution to society. Otherwise, $\alpha<0$ denotes a negative tax morale, i.e. paying high taxes is perceived as a waste of money. We can now rewrite the utilities of an high-income taxpayer as follows:

$U_{h}=\left\{\begin{array}{c}\widetilde{U}_{h N}=Y_{L}\left(1-t_{L}\right)+\left(Y_{H}-Y_{L}\right)\left(1-t_{H}+\alpha t_{H}\right) \text { if not audited } \\ \widetilde{U}_{h A}=Y_{L}\left(1-t_{L}\right)+\left(Y_{H}-Y_{L}\right)\left(1-t_{H}+\alpha t_{H}\right)+\zeta r(\beta-r) \text { if audited }\end{array}\right.$

whereas the utility of a dishonest high-income taxpayer is

$$
U_{d}=\left\{\begin{array}{c}
\widetilde{U}_{d N}=U_{d N}=\left(Y_{H}-Y_{L} t_{L}\right) \text { if not audited } \\
\widetilde{U}_{d A}=Y_{L}\left(1-t_{L}\right)+\left(Y_{H}-Y_{L}\right)\left(1-t_{H}\right)-M-\vartheta(\beta-r) \text { if audited }
\end{array}\right.
$$

Similarly to our analysis in Section 4, the expected utility of a dishonest agent is given by

$$
\mathbb{E}\left[\widetilde{U}_{d}\right]=p \widetilde{U}_{d A}+(1-p) \widetilde{U}_{d N}
$$

whereas the expected utility of a honest agent reads

$$
\mathbb{E}\left[\widetilde{U}_{h}\right]=p \widetilde{U}_{h A}+(1-p) \widetilde{U}_{h N}
$$

Also in this case word of mouth dynamics of the form (7) always admit the boundary states $r^{0}=0$ and $r^{1}=1$ as equilibria of the model. However with tax morale and social costs, there are two possible inner equilibrium shares of dishonest agents satisfying an isoutility condition where the score function

$$
y(r)=\mathbb{E}\left[\widetilde{U}_{d}\right]-\mathbb{E}\left[\widetilde{U}_{h}\right]
$$

is zero. By solving equation $y(r)=0$ with respect to $r$, we obtain the two equilibrium shares

$$
r_{1,2}^{*}=\frac{p \beta \zeta-\theta p \pm \sqrt{p\left(4 \zeta M p+p(\beta \zeta+\theta)^{2}-4 \zeta t_{H}(1-\alpha-p)\left(Y_{H}-Y_{L}\right)\right)}}{2 \zeta p}
$$

In what follows we provide a qualitative description of the dynamics of map (7) with score function defined in (11). The results of numerical analysis are based on the simple functional form for $G(y(r))$ previously employed by Bischi et al. (2003a,b) and Bischi et al. (2009), see footnote 6 for details. Notice, 
however, that the qualitative properties of the dynamics here considered do not depend on the exact specification of $G(y)$, but on the form of the utility differential $y(r)$. Thus, a functional form such as the one in footnote 6 is just a useful way to obtain in explicit form a dynamical system that models switching from honest to dishonest behavior and vice-versa.
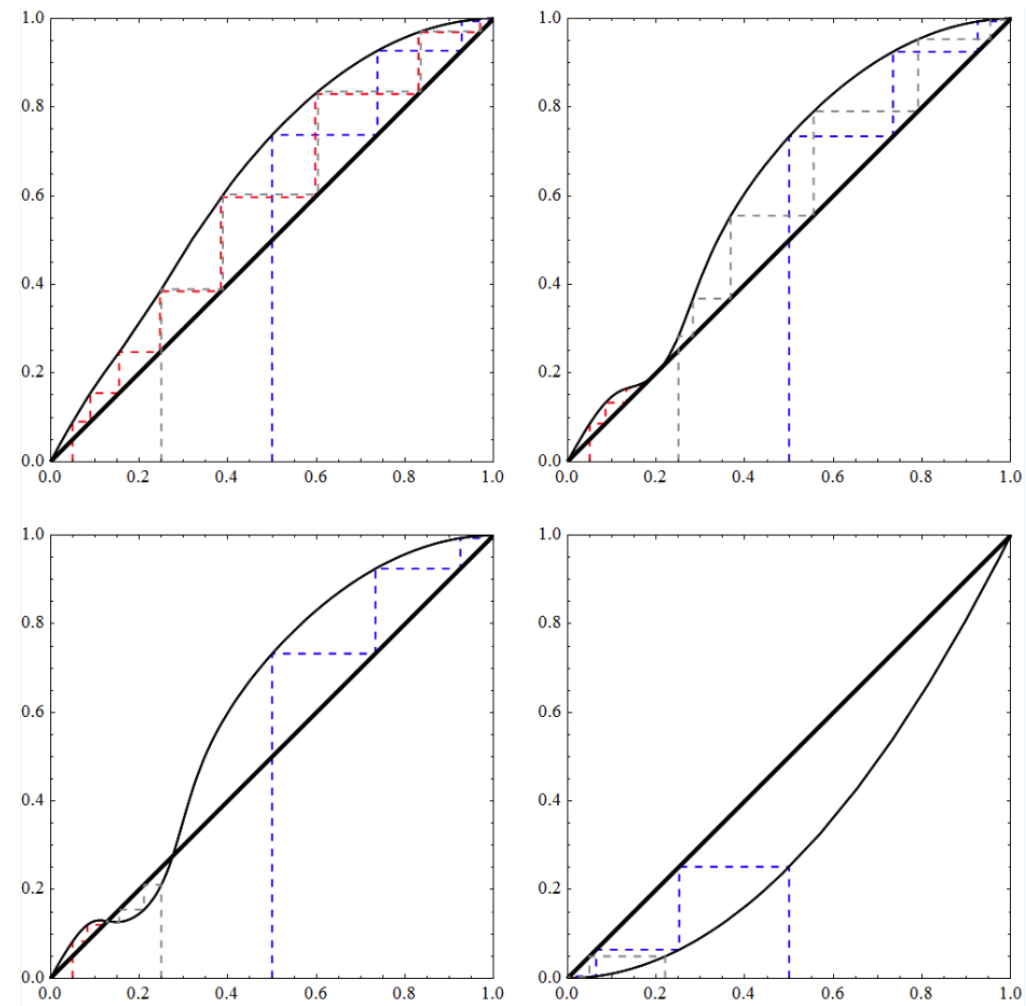

Figure 3: Cobweb plots of map $r_{t+1}=r_{t}\left[1+\left(1-r_{t}\right) G\left(y\left(r_{t}\right)\right)\right]$ with $G(y(r))=$ $\frac{2}{\pi} \arctan \left(\frac{\pi}{2} \lambda y(r)\right)$. Parameter values: $Y_{H}=92 ; Y_{L}=19 ; M=7.5 ; t_{L}=30 \%$; $t_{H}=56,5 \% ; \gamma=1 ; p=0.6 ; \theta=1 ; \zeta=1.8 ; \lambda=65$. (a) Top left $\alpha=0.276$ and $\beta=0.93$. (b) Top right $\alpha=0.276$ and $\beta=0.953$. (c) Bottom left $\alpha=0.276$ and $\beta=0.96$. (d) Bottom right $\alpha=0.3$ and $\beta=0.96$.

Let us start the analysis by a diagrammatic exercise that summarizes typical transition scenarios of the model as parameters are varied. Figure 3 provides four cobweb plots in the plane $\left(r_{t}, r_{t+1}\right)$ of word of mouth dynamics $(7)$, where the parameter values are $Y_{L}=19 ; Y_{H}=92 ; M=7.5 ; t_{L}=30 \% ; t_{H}=56,5 \%$; $\gamma=1 ; p=0.6 ; \theta=1 ; \zeta=1.8$ and $\lambda=65$. We consider in the four plots the same three initial conditions: $5 \%$ (red); $25 \%$ (grey) and 50\% (blue) of dishonest agents.

(a) The top left plot has $\alpha=0.276$ and $\beta=0.93$. The plot shows that in the long run the system converges to the boundary equilibrium in which all agents 
are dishonest. Inner equilibria $r_{1,2}^{*}$ in (12) are not feasible (they are not real numbers) for these parameter values.

(b) The top right plot depicts a cobweb diagram with the same parameters of plot (a) except for $\beta=0.953$. The increase in $\beta$ causes a fold bifurcation where the equilibria $r_{1,2}^{*}$ in (12) are created. In this case, trajectories with initial conditions below the threshold given by the inner steady state just created converge to it, whereas trajectories with initial conditions above the threshold converge to $r^{1}=1$ (where all individuals are dishonest in the long run).

(c) The bottom left plot describes a further increase in $\beta$, which is now $\beta=0.96$. Here $r_{1}^{*} \approx 12.9 \%<r_{2}^{*} \approx 27.54 \%$, see (12). For these parameter values the lower equilibrium $r_{1}^{*}$ is stable (here overshooting around equilibrium does not occur, since parameter $\lambda$ is sufficiently low) and the basin of attraction of $r_{1}^{*}$, i.e. all initial conditions of the share of dishonest agents, whose trajectories eventually converge to $r_{1}^{*}$, is $\mathcal{B}\left(r_{1}^{*}\right)=\left(0, r_{2}^{*}\right)$. Notice that trajectories starting with $5 \%$ and $25 \%$ of dishonest agents converge to $r_{1}^{*}$, while trajectories with initial conditions above $r_{2}^{*}$ converge to $r^{1}=1$ (e.g. the depicted trajectory with $50 \%$ of dishonest as initial condition).

(d) The bottom right plot describes the effects of an increase in tax morale $\alpha$. Specifically, parameters are the same as in case (c), except for $\alpha=0.3$. An increase in $\alpha$ produces two transcritical bifurcations (i.e. $r_{1}^{*}$ and $r_{2}^{*}$ are real numbers, but they do not belong to the set $(0,1))$. The increase in tax morale has induced the system to converge to the boundary equilibrium in which no individual evades taxes.

The various dynamics here described can also be appraised by observing the bifurcation diagrams in Figure 4, where stable equilibria are depicted as solid curves and unstable equilibria as dashed ones. Figure 4(a) (left plot) is obtained with the same set of parameters of Figure 3(a,b,c) and with $\beta$ varying in the interval $[0.5,1.6]$, whereas Figure 4(b) (right plot) presents a bifurcation diagram with the same parameters as Figure $4(\mathrm{a})$, but with $\beta=1.775$ and with $M$, the fine imposed to dishonest agents after auditing, ranging in the interval $[5,7.5]$.

The plots in Figure 4 show how the variation of a parameter in a given interval (here an increment in $\beta$ or in $M$ ) can produce transitions from cases where tax evasion tends to rise over time to cases where the opposite occurs, as the intuition would suggest; for intermediate values of the varying parameter ( $\beta$ and $M$ respectively), one or two equilibria of the type $r_{1,2}^{*}$ in (12) may exists.

The plots reported in Figure 3 and 4 provide important policy insights.

First, social norms (represented in our model by parameter $\beta$ ) play a critical role in defining the long run level of tax evasion in a society. Traditional fiscal/auditing policies in a society that is relatively lenient (low $\beta$ ) toward tax evasion will be ineffective and the society will see the level of tax evasion rise with time. If society, instead, is less forgiving of dishonest behavior (high $\beta$ ), then the level of tax evasion may converge to equilibria in which only a portion of the population engages in dishonest practices. This observation has important policy implications. Focusing on traditional fiscal/auditing policies (i.e. variations 

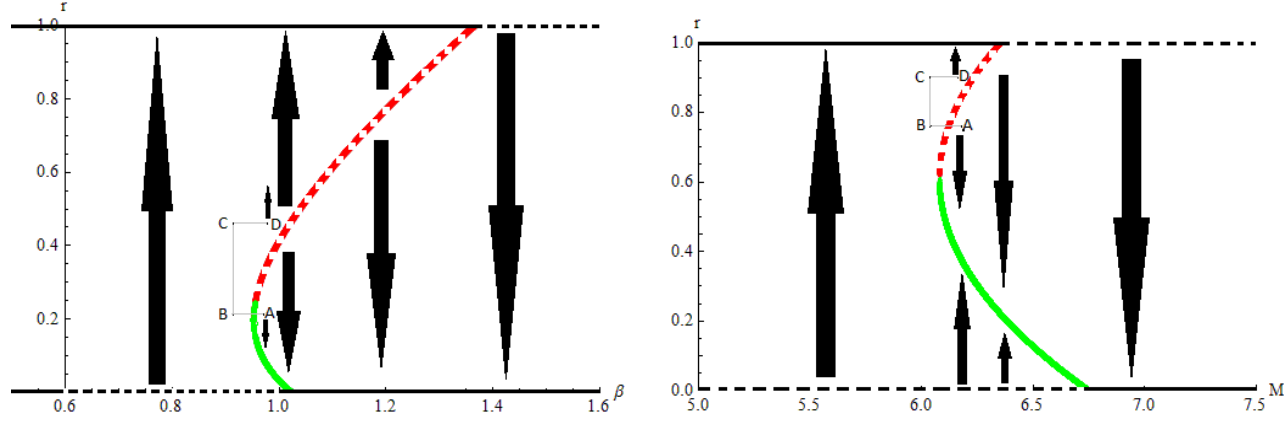

Figure 4: Bifurcation diagram of map (7) with parameters $Y_{L}=19 ; Y_{H}=92$; $t_{L}=30 \% ; t_{H}=56,5 \% ; \gamma=1 ; p=0.6 ; \theta=1 ; \zeta=1.8 ; \alpha=0.276$. Left: $M=7.5 \beta \in[0.5,1.6]$; right: $\beta=1.775$ and $M \in[5,7.5]$.

in tax rates, fines and auditing effort) may not be as effective as carefully understanding and influencing social norms. Forms of social-norms marketing (e.g. information campaigns, moral exhortation, fear-inducing messages, nudging ${ }^{21}$ ) could prove to be more effective (and less expensive) than standard approaches. Social-norms marketing could be used to generate shocks in the value of $\beta$ in the attempt to create a less lenient society toward tax evasion.

Another important insight provided by the plots in Figure 3 and 4 is that the initial conditions (i.e. the initial level of tax evasion) are critical to understand the evolution of tax evasion. Consider two economically and socially identical countries. Suppose that these two countries have the same parameter values and for both the evolutionary patterns of tax evasion can be described by plot $3(\mathrm{c})$ or by Figure 4. If the initial levels of tax evasion differ (e.g. above or below the dashed red curves of Figure 4(a) or 4(b), such as the points labeled $A$ and $D$ in those plots), however, the two countries will experience very different levels of tax evasion in the long run. This remark produces a very important caveat for those policymakers who may decide to adopt fiscal/auditing policies that have proved to be successful in other countries. Even if countries are rather similar economically and socially, if the initial level of tax evasion in the domestic country significantly differs, it is possible that the imported policies may produce dramatically different results.

Note, in addition, that the numerical analysis described in Figure 3 shows that the level of tax morale may significantly modify the evolutionary process of the level of tax evasion in a country. The countries described in plots (d) and (c) are identical, except for the level of tax morale. Starting with plot $3(\mathrm{~d})$, where tax morale is relatively high, we see that in the long run the system sees the whole population acting honestly. If tax morale decreases (perhaps because the government is seen by the population as corrupt and inefficient due to a scandal), the evolutionary process of tax evasion changes dramatically

${ }^{21}$ See Schultz (1999) and Schultz et al. (2008). 
and is now described by plot (c). This observation highlights the importance of carefully understanding tax morale and including its effects in the definition of fiscal/auditing policies. We mentioned above that social-norm marketing may be a more effective and cheaper instrument against tax evasion that traditional auditing policies. Our understanding of the effects of tax morale sheds some additional light on this matter and provides another important caveat. Psychology literature acknowledges that social-norm marketing, unfortunately, does not come without potential drawbacks. ${ }^{22}$ In particular, a known problem of social-norm marketing is the possibility of boomerang effects, i.e. the possibility that the attempt to induce a society to modify its social norms may produce perverse effects. This aspect of social-norm marketing further increases the importance of understanding the effects of tax morale. For example, a social campaign targeting moral exhortation (i.e. increase $\beta$ ), if accompanied by fear-inducing messages (for example the threat of forms of naming and shaming for dishonest individuals) may change the perception of individuals (who now may see the government as greedy and oppressive) and generate the perverse effect of reducing tax morale (i.e. lowering $\alpha$ ).

The bifurcation diagrams in Figure 4 provide also relevant information on the global dynamics of the system; in particular, they show that the system may exhibit irreversibility, which is a form of hysteresis (see Arnold (1992) for details). Let us suppose that the initial state of the system is as in point $A$ of Figure 4(a), where a reduction of dishonest behavior tends to occur. Now a reduction in $\beta$ takes the system to point $B$, where dishonest behavior spreads in the society; here, if the policymaker wanted to restore the system to the previous situation, setting $\beta$ to its initial level could be insufficient to invert the evolutionary tendency towards generalized tax evasion. In fact, if the system is in a point such as $C$, restoring $\beta$ to the initial level brings the system to point $D$, where the tendency is still to converge to equilibrium $r^{1}=1$ where all agents are dishonest. This irreversibility of the system resembles empirical observations as the poll tax in England discussed in the introduction of this paper.

The diagrams provide also insights regarding the effects of policies related to traditional auditing instruments. Suppose, for example, that $\beta$ is high enough so that in the long run converge to equilibrium $r^{0}=0$ is likely to occur. Because of this tendency toward honest behavior, the government may decide to reduce the fine $M$ and take the system to the situation depicted in Figure 4(b), where $\beta=1.775$ and where changes in the fine $M$ are depicted. For comparison purposes with Figure 4(a), start with $M=7.5$ and consider a gradual reduction of the fine. The share of dishonest agents rises continuously with the reduction of the fine $M$, but this only occurs up to the tipping point at $M \approx 6.1$ below which all agents find more profitable to evade taxes. Thus, small reductions of fines seem to induce small increments of the share of dishonest agents. However, this could hold only locally, i.e. only for given reductions of the fee and not for all reduction of it. Here, we also find the same kind of irreversibility of the action of the policymaker that we detected in the example of Figure 4(a), see

\footnotetext{
${ }^{22}$ See Schultz et al. (2007).
} 
the points $A, B, C, D$, where the discussion regarding hysteresis is similar to the case previously discussed.

\section{Conclusions}

In this paper we have stressed the importance of taking a long run perspective and considering dynamic adjustments when studying the effects of policies targeted at reducing tax evasion in a country. We have shown, in particular, that the social norms and the cultural framework where tax evasion takes place may play a very important role in guiding individuals' actions and, ultimately, the long run extent of tax evasion. In line with OECD recommendations, ${ }^{23}$ policymakers should consider adopting forms of social-norms marketing to increase awareness and social incentives and modify taxpayers' conduct. Indeed, standard instruments in the hands of fiscal policymakers, such as the probability of auditing or the size of the penalty when taxpayers are found guilty of tax evasion, may be less effective than forms of social-norms marketing attempting to influence social norms and reputational benefits/costs. In addition, compared to traditional fiscal instruments, social instruments tend to be less costly both financially (auditing and investigations are in general expensive) and politically (a government that declared to increase auditing effort and tax evasion fines may appear in some circumstances too oppressive and that may have a negative effect on tax morale). The paper also provided an important caveat. Given the importance of social norms, it would be foolish to expect that tax reforms that have been successful in a country will also necessarily produce positive results in another, if the societies in those countries are significantly different. Finally, the model discussed in the paper provides insights regarding the way tax rates may affect compliance. In particular, in contrast to results reported in previous literature, tax evasion tends to decrease when the highest tax rate in a progressive system is lowered. The possibility that lowering the high tax rate may help reducing tax evasion in the long run may explain why reforming the system to adopt a flat rate may have positive effect in increasing the honesty of taxpayers. In this sense, the paper points toward a possible explanation to the significant and surprising results of the introduction of a flat rate system in Russia in 2001.

\section{References}

Allingham, M. G. and Sandmo, A., (1972), "Income tax evasion: a theoretical analysis", Journal of Public Economics,1(3-4), 323-338.

Alm, J. and Torgler, B., (2006), "Culture differences and tax morale in the United States and in Europe", Journal of Economic Psychology, 27, 224-246.

Alm, J., Martinez -Vazquez, J., Torgler, B., (2010), "Developing Alternative Frameworks for Explaining Tax Compliance". Florence, Kentucky: Routledge.

Andreoni, J., Erard, B. and Feinstein, J., (1998), "Tax compliance", Journal of Economic Literature, 36, pages 818-860.

Arnold, V., (1992), "Catastrophe Theory", Springer, Berlin.

${ }^{23}$ See Daude et al. (2012). 
Barone, G. and Mocetti, S., (2011), "Tax morale and public spending inefficiency", International Tax Public Finance, 18, 724-749.

Becker, G., (1968), "Crime and Punishment: An Economic Approach", Journal of Political Economy, 76, pp. 169-217.

Bénabou, R. and Tirole, J., (2006), "Incentives and Prosocial Behavior", American Economic Review, 96(5), 1652-1678.

Besley, T. and Persson, T., (2014), "Why Do Developing Countries Tax So Little?", Journal of Economic Perspectives, 28(4), pages 99-120.

Besley, T. J., Jensen, A., Persson, T., (2015), "Norms, Enforcement, and Tax Evasion," CEPR Discussion Papers 10372.

Bischi G.I., Dawid, H., Kopel, M., (2003a), "Spillover Effects and the Evolution of Firm Clusters", Journal of Economic Behavior and Organization, 50 47-75.

Bischi G.I., Dawid, H., Kopel, M., (2003b), "Gaining the Competitive Edge Using Internal and External Spillovers: A Dynamic Analysis", Journal of Economic Dynamics and Control, 27, 217-219.

Bischi G.I., Lamantia F., Radi D., (2015), "An evolutionary Cournot model with limited market knowledge", Journal of Economic Behavior $\mathcal{E}$ Organization, 116, 219-238.

Bischi G.I., Lamantia F., Sbragia L., (2009), "Strategic interaction and imitation dynamics in patch differentiated exploitation of fisheries", Ecological Complexity, 6, 353-362.

Chetty, R., (2009), "Is the taxable income elasticity sufficient to calculate deadweight loss? The implication of evasion and avoidance", Americal Economic Journal: Economic Policy, 1, pages 31-52.

Cressman, R., (2003), "Evolutionary dynamics and extensive form games", The MIT Press, Cambridge.

Cumming, R. G., Martinez -Vasquez, J., McKee, M., Torgler, B., (2009), "Tax morale affects tax compliance: Tax morale affects tax compliance: Evidence from surveys and an artefactual field experiment", Journal of Economic Behavior and Organization, 70, 447-457.

Daude, C., Gutiérrez, H. and Melguizo, A., (2012), "What Drives Tax Morale?",OECD Development Centre Working Papers 315, OECD Publishing.

Dawid, H., (1999), "On the dynamics of word of mouth learning with and without anticipations", Annals of Operations Research, 89, 273-295.

De Giovanni, D., Lamantia, F., (2016), "Control delegation, information and beliefs in evolutionary oligopolies", Journal of Evolutionary Economics, 26-5, 1089-1116.

DeBacker, J., Heim, B.J. and Tran, A., (2015), "Importing corruption culture from overseas: evidence from corporate tax evasion in the United States", Journal of Financial Economics, 117(1), pages 122-138.

Droste, E., Hommes C., Tuinstra, J., (2002), "Endogenous fluctuations under evolutionary pressure in Cournot competition", Games and Economic Behavior, 40 (2), 232-269.

Dwenger, N., Kleven, H., Rasul, I. and Rincke, J., (2016), "Extrinsic and 
intrisic motivation for tax compliance: evidence from a field experiment in Germany", American Economic Journal: Economic Policy, 8 (3), pages 203-232.

Ellison, G., Fudenberg, D., (1995), "Word-of-mouth communication and social learning", Quarterly Journal of Economics, CX, 93-125.

Filippin, A., Fiorio, C.V. and Viviano, E., (2013), "The effect of tax enforcement on tax morale", European Journal of Political Economy, 32, 320-331.

Freire-Serén M.J. and Panadés, J., (2013), "Do Higher Tax Rates Encourage/Discourage Tax Compliance?", Modern Economy, 4(12), 809-817.

Frey, B. S., (1983), "Deterrence and tax morale in the European Union", European Review, 11(3), 385-406.

Frey, B.S. and Torgler, B., (2007), "Tax morale and conditional cooperation", Journal of Comparative Economics, 35, 136-159.

Gangl, K., Hofmann, E. and Kirchler, E., (2015), "Tax authorities' interaction with taxpayers: A conception of compliance in social dilemmas by power and trust", New Ideas in Psychology, 37, 13-23.

Gorodnichenko, Y., Martinez-Vazquez, J., Sabirianova K., (2009), "Myth and Reality of Flat Tax Reform: Micro Estimates of Tax Evasion Response and Welfare Effects in Russia," Journal of Political Economy, 117(3), pages 504-554, 06.

Hallsworth, M., List, J.A., Metcalfe, R.D. and Vlaev, I., (2014), "The behavioralist as tax collector: using natural field experiments to enhance tax compliance", NBER Working Paper 20007.

Kim, Y., (2003), "Income distribution and equilibrium multiplicity in a stigma-based model of tax evasion", Journal of Public Economics, 87, 15911616.

Kirchler, E., (2007), "The Economic Psychology of Tax Behaviour", Cambridge University Press, Cambridge U.K.

Kleven, H. J., Knudsen, M.B., Thustrup Kreiner, C., Pedersen, S. and Saez, E., (2011), "Unwilling or unable to cheat? Evidence from a tax audit experiment in Denmark", Econometrica, 79, pages 651-692.

Kopel, M., Lamantia, F., Szidarovszky, F., (2014), "Evolutionary Competition in a Mixed Market with Socially Concerned Firms", Journal of Economic Dynamics \& Control, 48, 394-409.

Kountouris, Y., and Remoundou, K., (2013), "Is there a cultural component in tax morale? Evidence from immigrants in Europe", Journal of Economic Behavior and Organization, 96, pages 104-119.

Lago-Peñas, I. and Lago-Peñas, S., (2010), "The determinants of tax morale in comparative perspective: evidence from European countries", European Journal of Political Economy, 26, 441-453.

Lamantia, F., Pezzino, M., (2016), "Evolutionary Efficacy of a Pay for Performance Scheme with Motivated Agents", Journal of Economic Behavior and Organization, 125, 107-119.

Lubian, D. and Zarri, L., (2011), "Happiness and tax morale: an empirical analysis", Journal of Economic Behavior and Organization, 80, 233-243.

Luttmer, E.F.P. and Singhal, M., (2014), "Tax morale", Journal of Economic Perspectives, 28, pages 143-168. 
Myles, G.D. and Naylor, R.A., (1996), "A model of tax evasion with group conformity and social customs", European Journal of Political Economy, 12, 49-66.

Schultz, P.W., (1999), "Changing behavior with normative feedback interventions: A file experiment on curbside recycling", Basic and Applied Social Psychology, 21, 25-36.

Schultz, P. W., Nolan, J.M., Cialdini, R.B., Goldstein, N.J., Griskevicius, V., (2007), "The constructive, destructive and reconstructive power of social norms", Psychological Science, 18 (5), 429-434.

Schultz, P.W., Tabanico, J. and Rendón, T., (2008), "Normative beliefs as agents of influence: Basic process and real-world applications". In R. Prislin and W. Crano (Eds.), Attitudes and persuasion. New York: Psychology Press.

Slemrod, J., Weber, C. (2012) "Evidence of the invisible: toward a credibility revolution in the empirical analysis of tax evasion and the informal economy", International Tax and Public Finance, 19, pages 25-53.

Slemrod, J., Yitzhaki, S., (2002), "Tax avoidance, evasion, and administration". In A. J. Auerbach and M. Feldstein (Eds.), Handbook of Public Economics, edition 1, volume 3, chapter 22, pages 1423-1470 Elsevier.

Sutcliffe, A., Wang, D. and Dunbar, R., (2012), "Social Relationships and the Emergence of Social Networks", Journal of Artificial Societies and Social Simulation, 15 (4), 3.

Terry, D.J., Hogg, M.A., (2001), "Attitudes, behavior, and social context: The role of norms and group membership in social influence processes". In J.P. Forgas and K.D. Williams (Eds.), Social Influence: Direct and indirect processes. (pp. 253-270). Philadelphia: Psychology Press.

Torgler, B., (2007), "Tax compliance and morale. A Theoretical and Empirical Analysis". Edward Elgar, Chentelham.

Traxler, C., (2010),"Social norms and conditional cooperative taxpayers", European Journal of Political Economy, 26, 89-103.

van Dolder D., Buskens V. (2014) "Individual Choices in Dynamic Networks: An Experiment on Social Preferences". PLoS ONE, 9(4): e92276. doi:10.1371/journal.pone.0092276.

Weibull, J., (1995), Evolutionary Game Theory. The MIT Press, Cambridge.

Yitzhaki, S., (1974), "Income tax evasion: a theoretical analysis", Journal of Public Economics, 3(2), 201-202. 


\section{Appendix}

\section{Proposition A.1}

Consider the adjustment dynamics modelled by map (7) and the thresholds levels $\widetilde{t}_{H}$ and $\widehat{t}_{H}$ in (5).

- Assume that $\zeta>\theta>0$.

- When

$$
t_{L}<t_{H}<\widetilde{t}_{H}
$$

the boundary equilibrium $r^{0}=0$ is asymptotically stable with basin of attraction $\mathcal{B}\left(r^{0}\right)=[0,1)$, the boundary equilibrium $r^{1}=1$ is unstable and the inner equilibrium $r^{*}$ in (4) is not meaningful, as $r^{*} \notin[0,1]$;

- When

$$
\widetilde{t}_{H}<t_{H}<\widehat{t}_{H}
$$

the boundary equilibria $r^{0}=0$ and $r^{1}=1$ are unstable and the inner equilibrium $r^{*}$ in (4) is locally asymptotically stable with basin of attraction $\mathcal{B}\left(r^{*}\right)=(0,1)$ provided that the following "non-overshooting" condition holds:

$$
G^{\prime}(0) \in\left(0, \frac{2}{p\left(1-r^{*}\right) r^{*}(\zeta-\theta)}\right)
$$

At $G^{\prime}(0)=\frac{2}{p\left(1-r^{*}\right) r^{*}(\zeta-\theta)}$, equilibrium $r^{*}$ looses stability through a period-doubling bifurcation, with the appearance of cyclic or chaotic motion as parameter $G^{\prime}(0)$ is further increased.

- When

$$
\widehat{t}_{H}<t_{H}<1
$$

the boundary equilibrium $r^{1}=1$ is asymptotically stable with basin of attraction $\mathcal{B}\left(r^{1}\right)=(0,1]$, the boundary equilibrium $r^{0}=0$ is unstable and the inner equilibrium $r^{*}$ in (4) is not meaningful;

$-A t$

$$
t_{H}=\widetilde{t}_{H}
$$

a transcritical bifurcation occurs, at which equilibria $r^{*}$ and $r^{0}$ merge and exchange their stability properties;

$-A t$

$$
t_{H}=\widehat{t}_{H}
$$

a transcritical bifurcation occurs, at which equilibria $r^{*}$ and $r^{1}$ merge and exchange their stability properties.

- Assume that $\theta>\zeta>0$. 
- When

$$
t_{L}<t_{H}<\widehat{t}_{H}
$$

the boundary equilibrium $r^{0}=0$ is asymptotically stable with basin of attraction $\mathcal{B}\left(r^{0}\right)=[0,1)$, the boundary equilibrium $r^{1}=1$ is unstable and the inner equilibrium $r^{*}$ in (4) is not meaningful;

- When

$$
\widehat{t}_{H}<t_{H}<\widetilde{t}_{H}
$$

the inner equilibrium $r^{*}$ in (4) is unstable and constitutes the basin boundary of the locally stable fixed points $r^{0}=0$ and $r^{1}=1$, with basins of attraction $\mathcal{B}\left(r^{0}\right)=\left[0, r^{*}\right)$ and $\mathcal{B}\left(r^{1}\right)=\left(r^{*}, 1\right]$ respectively;

- When

$$
\tilde{t}_{H}<t_{H}<1
$$

the boundary equilibrium $r^{1}=1$ is locally asymptotically stable with basin of attraction $\mathcal{B}\left(r^{1}\right)=(0,1]$, the boundary equilibrium $r^{0}=0$ is unstable and the inner equilibrium $r^{*}$ in (4) is not meaningful;

$-A t$

$$
t_{H}=\widehat{t}_{H}
$$

a transcritical bifurcation occurs, at which equilibria $r^{*}$ and $r^{1}$ merge and exchange their stability properties;

$-A t$

$$
t_{H}=\widetilde{t}_{H}
$$

a transcritical bifurcation occurs, at which equilibria $r^{*}$ and $r^{0}$ merge and exchange their stability properties.

Proof. By the properties of map (7), if $G(y(r))>0[<0]$ for all $r \in(0,1)$, then the generic trajectory starting at initial condition $r_{0} \in(0,1)$ will converge to $r_{1}=1\left(r^{0}=0\right)$. Applying this property, we get the stability conditions for the boundary equilibria. Linearization of $(7)$ gives

$$
\frac{d r_{t+1}}{d r_{t}}=1+\left(1-2 r_{t}\right) G\left(y\left(r_{t}\right)\right)+r_{t}\left(1-r_{t}\right) G^{\prime}\left(y\left(r_{t}\right)\right) y^{\prime}\left(r_{t}\right)
$$

from which, since at $r^{*}$ it is $G\left(y\left(r^{*}\right)\right)=0$, it is

$$
{\frac{d r_{t+1}}{d r_{t}}}_{r_{t}=r^{*}}=1-p r^{*}\left(1-r^{*}\right)(\zeta-\theta) G^{\prime}(0)
$$

From the properties of $G($.$) , it must be G^{\prime}(0)>0$, so that a stable fixed point must satisfy condition $\zeta>\theta$. Clearly, such a $r^{*}$ satisfies condition

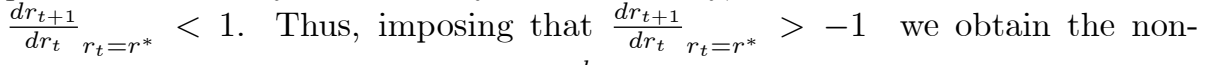
overshooting condition (13). Setting $\frac{d r_{t+1}}{d r_{t}} r_{t}=r^{*}=-1$, we obtain the condition for the period-doubling bifurcation and the onset of periodic/chaotic behavior. See also Lamantia and Pezzino (2016) for details. 